\title{
Analysis, evaluation and innovative methodologies to prevent coastal erosion
}

\author{
G. Foti \& C. L. Sicilia \\ DICEAM Department, "Mediterranea" University, \\ Reggio Calabria, Italy
}

\begin{abstract}
The main characteristic of a coastal system is its variability. Many factors are involved in the evolution of the shoreline, which can depend on the weather, on geology, and on the presence or absence of river mouths. They can also depend on the urbanization of the coasts or of the interior areas.

In order to prevent coastal erosion, it is necessary to clearly understand the interaction of so many factors. In this regard both geological and historical aspects, experimental and theoretical models have to be considered in order to analyze the extreme variability of the system.

This paper is divided into three parts. The first is concerned with the historical variation of the Calabria shoreline, evaluated through cartographic analysis. All data are provided by the Calabria Basin Authority and the analysis is made with GIS software. The first part ends with the identification of the areas characterized by coastal erosion. The second part is concerned with the evaluation of the causes of the erosion and the identification of the best type of intervention. The last part is concerned with the latest approaches to coastal dynamic, in particular Barbaro et al. ("Set-up due to random waves: influence of the directional spectrum", Proc. of the $30^{\text {th }}$ Int. Conf. on Ocean, Offshore and Artic Eng., Rotterdam, 2011 and "A probabilistic approach for the run-up estimation", Proc. of the $5^{\text {th }}$ Int. Short Conf. on Appl. Coastal Res., Aachen, 2011) to evaluate the set-up and the run-up, Tomasicchio et al. ("A general longshore transport model. Coastal Eng., 71, pp. 28-36, 2013), to evaluate the total longshore transport rate and Barbaro and Foti, "Shoreline behind a breakwater: comparison between theoretical models and field measurements for
\end{abstract}


the Reggio Calabria sea", J. of Coastal Res., 29(1), pp. 216-224, 2013), to evaluate the shoreline behind a breakwater.

Keywords: coastal erosion, beach morphodynamics, shoreline evolution, run-up, set-up, longshore sediment transport, coastal structures.

\section{Introduction}

The development of coastal lands and the progressive depopulation of mountains have led to two-thirds of the population living within a range of $200 \mathrm{~km}$ of the coast. This change has increased problems and risks linked to coastal erosion, calling for stricter monitoring in order to protect coasts and the population.

The prediction and management of shoreline evolution are necessary to protect coasts. Shoreline evolution is caused by many physical factors, such as intensity and duration of a sea storm (Arena et al. [5]), design wave (Barbaro [6]), maximum wave forces on structures (Barbaro [7]; Boccotti et al. [8, 9]; Romolo et al. [10]), longshore sediment transport (Tomasicchio et al. [3]), set-up (Barbaro et al. [1]), run-up (Barbaro et al. [2]). Shoreline evolution that can be described on three different temporal scales: geological (lasting for hundreds of years), long-term (lasting from a few years to tens of years), and short-term (lasting for a few months). Long-term evolution depends on wave conditions and sea currents, while short-term evolution depends on typical surf-zone phenomena such as the difference between summer and winter profiles.

Coastal erosion can be limited by two different kinds of actions: soft intervention (beach nourishment) and hard intervention (the use of structures such as breakwaters and groins). Breakwaters are structures placed parallel to the coast, dissipating wave energy and slowing offshore sediment transport. In this way, sediment can accumulate behind the structures and allow the shoreline to advance. If the shoreline reaches the breakwater, a feature known as a tombolo occurs; otherwise, the formed feature is known as a salient. Groins are structures placed orthogonal to the coast causing beach accretion at the wave beaten side of the groin and beach erosion at the lee side of the structure. The principal responsible for beach deformation near coastal structures is the diffraction effect.

Coastal processes can be approximated only through the use of analytical or numerical models because of the great number of parameters involved (De Vriend et al. [11]) and such models can also consider the presence of coastal structures. These models each concentrate on a particular part of the phenomenon as a whole and this is important in the definition of approximation limits (De Vriend [12]) in order to choose the best model to use.

Models can be static or dynamic; and this distinction depends on the kind of equilibrium profile reached. In static models all forces are balanced; unfortunately, this configuration is reached only when wave conditions are constant over time, and it is nearly impossible to reach a stationary profile.

Nevertheless, static models can be applied if the reference time is long enough and if average wave conditions do not change considerably from one year to another (near-equilibrium conditions). 
Principal analytical and numerical models have been studied and compared by Hanson and Larson [13], Kamphuis [14], and Hanson et al. [15]. These authors also analyzed the main phenomena relating to shoreline evolution (refraction, wave breaking, and longshore transport rate).

\section{Description of Calabria region}

Calabria (Fig. 1) is a southern region of the Italian peninsula; the area is $15,079 \mathrm{~km}^{2}$ with a population of about two million people. This region has 5 provinces and 409 towns (116 of them are located in a coastal area). The Calabria shoreline has a length of about $700 \mathrm{~km}$. The Tyrrhenian side is long, at about $250 \mathrm{~km}$; the Ionian side is long, at about $450 \mathrm{~km}$.

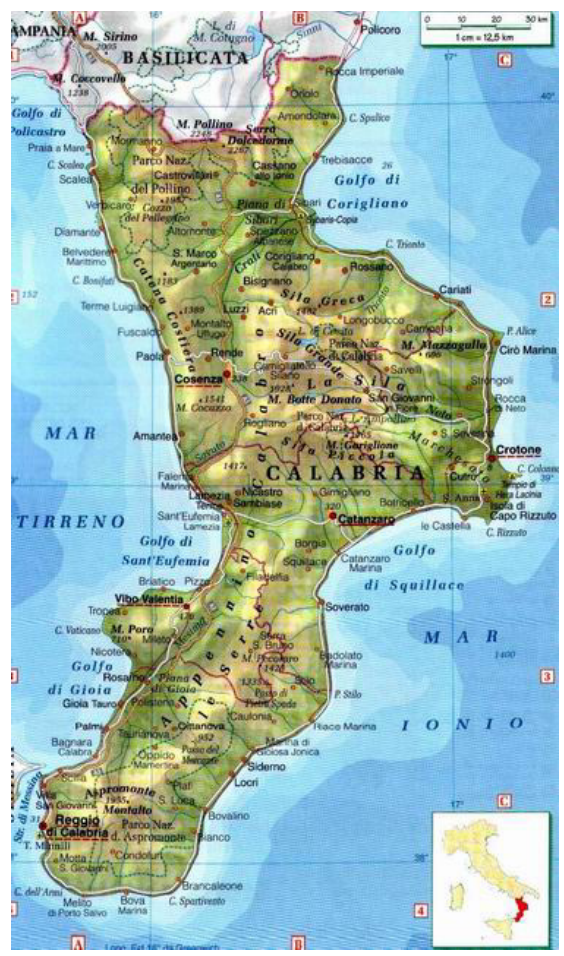

Figure 1: Calabria region.

\section{Evaluation of coastal erosion in Calabria}

The evaluation of coastal erosion in Calabria was made through cartographic analysis of the historical variation of the Calabria shoreline. By the open source software Quantum GIS 1.8.0 'Lisboa' the shoreline displacement has been estimated (the estimation has been based on the latest orthophoto provided by the 
Calabria Basin Authority in 2008). With this purpose, the shoreline has been distinguished in beaches, cliffs, rocky coasts and anthropogenic beaches. Moreover, a database containing information about ports, coastal structures (barriers, groins, mixed structures, etc.) has been created. A particular layer has been created for each mentioned element and each one has been associated to the town where it is located. Next, the shoreline has been compared to the ones obtained by previous measurements. Specifically, it has been compared to the shorelines measured in 1958 (given by the "Cassa del Mezzogiorno" cartography), in 1985 (IGM) and in 1998 (Calabria Region orthophoto). Figure 2 shows the layout utilized and gives a global view of the Calabria shoreline (as the computations are time consuming; only the orthophotos of the coastal areas have been used). Table 1 shows a summary of the elements and a size-based classification. Table 2 shows a summary pertaining to the structures.

Table 1: $\quad$ Summary of the elements and size-based classification.

\begin{tabular}{|c|c|c|c|c|c|c|}
\hline Layer & $\begin{array}{c}\text { Amount of } \\
\text { elements }\end{array}$ & $\begin{array}{c}\text { Total length } \\
{[\mathrm{km}]}\end{array}$ & $\begin{array}{c}>1 \\
\mathrm{~km}\end{array}$ & $\begin{array}{c}0.5-1 \\
\mathrm{~km}\end{array}$ & $\begin{array}{c}0.1-0.5 \\
\mathrm{~km}\end{array}$ & $\begin{array}{c}<0.1 \\
\mathrm{~km}\end{array}$ \\
\hline Beach & 977 & 577 & 140 & 65 & 327 & 444 \\
\hline Rocky coasts & 223 & 46 & 8 & 14 & 86 & 117 \\
\hline Cliffs & 104 & 54 & 15 & 18 & 45 & 26 \\
\hline $\begin{array}{c}\text { Anthropogenic } \\
\text { beaches }\end{array}$ & 76 & 5 & 0 & 1 & 13 & 62 \\
\hline
\end{tabular}

Table 2: $\quad$ Amount of structures.

\begin{tabular}{|c|c|}
\hline Structure & Amount \\
\hline Port & 22 \\
\hline Barrier & 138 \\
\hline Groin & 192 \\
\hline Grazing cliff & 408 \\
\hline $\begin{array}{c}\text { Mixed } \\
\text { structures }\end{array}$ & 54 \\
\hline
\end{tabular}

The previous tables emphasize that Calabria is a rather heterogeneous location from a orographic perspective, where there is an alternation of long beaches (globally $577 \mathrm{~km}$ ) and rocky coasts, both low (length $46 \mathrm{~km}$ ) and high (length $54 \mathrm{~km}$ ). 977 beaches have been identified; $15 \%$ of these are longer than $1 \mathrm{~km}$ (the longest is in Rossano, on the Ionian side: $13.5 \mathrm{~km}$ ). Almost all rocky coasts are located in Capo Vaticano (Ricadi and Joppolo), Monte Sant'Elia (in Bagnara Calabria, Palmi and Seminara) and Capo Rizzuto (in Crotone and Isola di Capo Rizzuto).

Calabria is complex from an anthropogenic perspective, as well. Indeed, there are largely anthropogenic areas (in particular is Crotone, Reggio Calabria, Vibo Valentia and the Tyrrhenian side of Cosenza) and natural ones (mainly in the Ionian area). Specifically, 76 anthropogenic beaches have been identified, among them, Chianalea, which was built directly on the sea. 


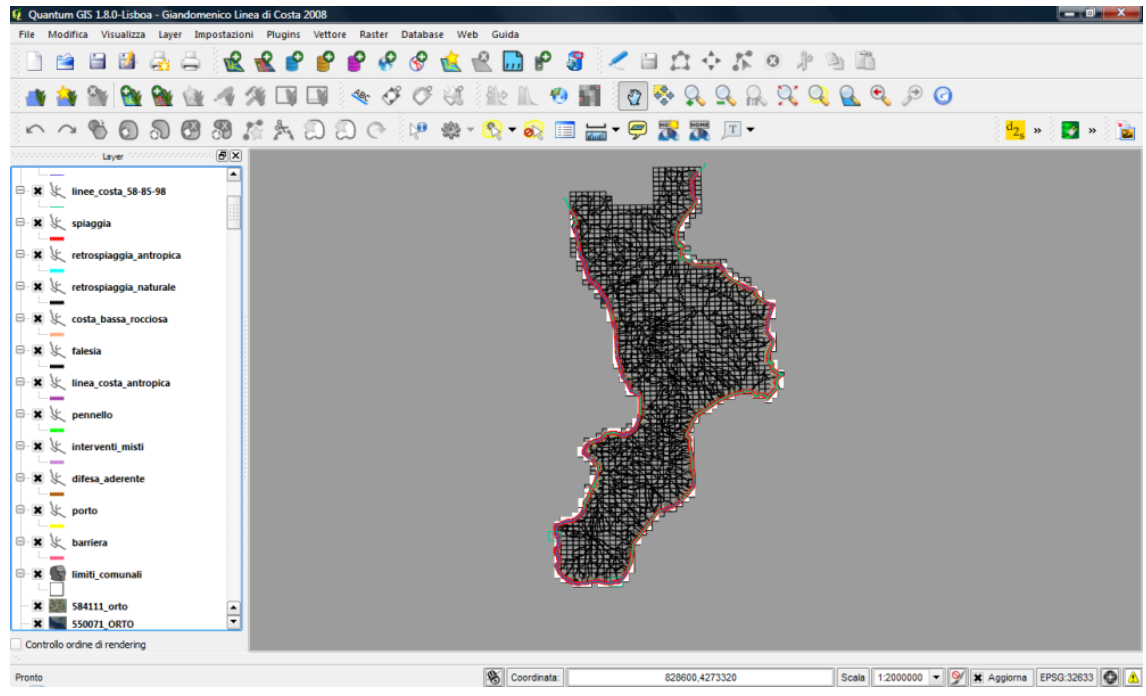

Figure 2: $\quad$ Layout of the software. Left panel: layer list.

The identification procedure has found 792 structures and 22 ports having various sizes and purposes. The most erosion processes were measured close to anthropogenic locations, built quite close to the shoreline, and into the rivers. Further, all the ports (except for the small touristic ports of Palmi and Badolato) have markedly modified the shoreline equilibrium, by increasing the erosion process. However, for a port constructed backwards, at the shoreline (such as in Gioia Tauro and in Cassano allo Ionio), the erosion has been quite limited.

\section{Latest approaches to coastal dynamic}

This section summarizes some of the most recent models involved in the estimation of shoreline change.

\subsection{Set-up and run-up}

Waves approaching the coasts dissipate most of the energy by breaking across the surf zone. However, a part of this energy is partially converted into potential energy as run-up on the foreshore of the beach (Hunt [16]).

Wave run-up (defined as the time-varying location of the shoreward edge of water in front of a beach) is often expressed in terms of a vertical excursion consisting of two components: a super elevation of the mean water level (MWL), called a wave set-up, and fluctuations about that mean, known as swash.

The exact evaluation of the run-up and set-up and the understanding of the elements, on which they depend, are two fundamental aspects for the estimation of coastal risks and for the planning and management of protection projects. 
Indeed, the run-up is one of the causes of erosion both of beaches and of coastal dunes (Ruggiero et al. [17]; Sallenger [18]) and the set-up is one of the key factors in the verification of flooding of coastal areas.

\subsubsection{Set-up}

The new expression of set-up due to irregular waves (Barbaro et al. [1]) was obtained following the logic of Longuet-Higgins [19] for regular waves, and following the logic of Barbaro and Martino [20]. The model is based on the assumption that the contour lines are straight and parallel to the $x$-axis and that the seabed is flat. The fluid has been assumed inviscid and the flow has been assumed irrotational up to the breaker line. In this context, the analytical expression of the set-up $S_{U}$ is derived, given the expression of the radiation stress and the set-down $S_{D}$ for random waves and, in a non-dimensional form related to the wave spectrum at infinite water depth, it is:

$$
\begin{aligned}
& \frac{S_{u}}{\sigma_{0}}=-\frac{S_{D} / \sigma_{0}}{1-\frac{S_{D}}{\sigma_{0}} \frac{L_{p_{0}}}{d_{b}} \frac{\sigma_{0}}{L_{p_{0}}}}+\frac{1 / 2}{\frac{d_{b}}{L_{p_{0}}} \frac{L_{p_{0}}}{\sigma_{0}}-\frac{S_{D}}{\sigma_{0}} \int_{0}^{\infty} \int_{0}^{2 \pi} S_{0}\left(\omega, \vartheta_{0}\right) d \vartheta_{0} d \omega}\left\{\int_{0}^{\infty} \int_{0}^{2 \pi} S_{0}\left(\omega, \vartheta_{0}\right)\right. \\
& \times \frac{\sinh (2 k d)}{\tanh (k d)[\sinh (2 k d)+2 k d]} \sqrt{\frac{1-\sin ^{2} \vartheta_{0}}{1-\sin ^{2} \vartheta_{0} \tanh ^{2}(k d)}} \\
& \left.\times\left[\frac{2 k d}{\sinh (2 k d)}\left(2-\sin ^{2} \vartheta_{0} \tanh ^{2}(k d)\right)+1-\sin ^{2} \vartheta_{0} \tanh ^{2}(k d)\right] d \vartheta_{0} d \omega\right\},
\end{aligned}
$$

where $\sigma_{0}$ is the variance, $L_{P_{0}}$ is the wavelength related to the dominant wave period in deep water, $d_{b}$ is the water depth at breaking, $S_{0}$ is the directional spectrum of the surface displacement in deep water, $\omega$ is the angular frequency, $\vartheta_{0}$ is the angle of the propagation direction and the y-axis, $k$ is the wave number and $d$ is the water depth.

Also, following the logic of Boccotti et al. [21] the effect of the assumed directional spectrum is investigated. In particular, set-up is estimated by considering the following frequency spectra: Pierson and Moskowitz [22], JONSWAP [23] and Ochi and Hubble [24]. Further, influence of the spreading function is investigated by assuming a cosine-power [25] and a hyperbolic spreading function [26]. It has been shown that set-up is mostly influenced by the assumed frequency spectrum. The maximum and the minimum set-up are due, respectively, to the Ochi-Hubble and the JONSWAP spectrum. The spreading function influence has been investigated; it has been shown that, for a fixed frequency spectrum, the mean difference in the determination of the set-up for a cosine-power and a hyperbolic spreading function is $5 \%$. The difference is about $15 \%$ for an oblique dominant direction, while for an orthogonal dominant direction the difference is less than $1 \%$.

\subsubsection{Run-up}

Barbaro et al. [2] has described a probabilistic approach for estimating run-up levels. It is based on the Equivalent Triangular Storm (ETS) model proposed by 
Boccotti in the eighties (Arena et al. [5]; Boccotti [27]) and has been applied in conjunction with the empirical relation proposed by Stockdon et al. [28].

The probabilistic approach has been applied for estimating the return period of a storm in which run-up exceeds a fixed threshold. Further, the mean persistence of run-up above a fixed threshold has been calculated. This analysis has shown that characteristics of the waves and of the beach under examination are needed for a probabilistic estimation of the run-up.

The return period of a run-up level higher than a fixed threshold is:

$$
R\left(R_{u 2 \%}>X\right)=\left[\sum_{i=1}^{N} \frac{1}{R\left(H_{s}>h ; \theta_{i}-\Delta \theta / 2<\theta<\theta_{i}+\Delta \theta / 2\right)}\right]^{-1},
$$

where $R\left(H_{s}>h ; \theta_{i}-\Delta \theta / 2<\theta<\theta_{i}+\Delta \theta / 2\right)$ is the return period of a sea storm in which the significant wave height $H_{s}$ exceeds a fixed threshold $h$ and the dominant direction $\theta$ ranges from $\theta_{\mathrm{i}}-\Delta \theta / 2$ to $\theta_{\mathrm{i}}+\Delta \theta / 2$ which are explicitly calculated by the ETS model and it is given by the equation (Arena et al. [29]):

$$
\begin{aligned}
& R\left(H_{s}>h ; \theta_{i}-\Delta \theta / 2<\theta<\theta_{i}+\Delta \theta / 2\right)= \\
& =\frac{\bar{b}\left(h ; \theta_{i}-\Delta \theta / 2<\theta<\theta_{i}+\Delta \theta / 2\right)}{\exp \left[-\left(\frac{h}{w_{\alpha}}\right)^{u}\right]\left[1+u\left(\frac{h}{w_{\alpha}}\right)^{u}\right]-\exp \left[-\left(\frac{h}{w_{\beta}}\right)^{u}\right]\left[1+u\left(\frac{h}{w_{\beta}}\right)^{u}\right]},
\end{aligned}
$$

where $u, w_{\alpha}$ and $w_{\beta}$ are parameters that depend on the location under examination and $\bar{b}\left(h ; \theta_{i}-\Delta \theta / 2<\theta<\theta_{i}+\Delta \theta / 2\right)$ is a base-significant wave height regression of the sea states where the direction ranges from $\theta_{i}-\Delta \theta / 2$ to $\theta_{i}+\Delta \theta / 2$.

\subsection{Longshore transport}

Typically, a coastal structure is intended as a body which reduces and absorbs the wave energy. In this sense, both a rubble mound breakwater and a beach are bodies made of non-cohesive units functioning as a coastal structure. Different coastal structures can be identified by means of the stability number (Van der Meer [30]). The knowledge of the longshore transport and its cross-shore distribution pattern in the surf zone are central in coastal engineering studies and practical engineering applications require accurate predictions of the longshore transport. A possible classification of the longshore transport methods distinguishes three types. The first type comprises the energetic methods and can be divided into two sub-types: the energy flux approach and the stream power approach. The energy flux approach was developed specifically for coastal sediment transport, while the stream power approach is of more general application to any sediment transport situation, including fluvial environment. The second type is based on the force-balance method which, classically, is the alternative method to the stream power approach in predicting sediment transport. The third type comprises formulae which were derived by a 
dimensional analysis method with parameters which are thought to be of importance for longshore transport.

Tomasicchio et al. [3], following the logic of Lamberti and Tomasicchio [31], proposes a general model to determine the total longshore transport at any given coastal mound. It considers an energy flux approach combined with an empirical/statistical relationship between the wave induced forcing and the number of moving units. As in the case of well popular formulae (e.g. CERC formula), the new model does not distinguish between bed load and suspended transport. Calibration and verification of the new longshore transport model have been conducted with nine high quality data sets from field and laboratory observations. The predictive capabilities of the model have also been favourably verified against some of the existing formulae adopted for the calculation of the longshore transport rate at different coastal mounds. The proposed model gives a better agreement with the observed data with respect to other investigated formulae, for all types of considered coastal bodies: berm or reshaping breakwaters, rock and cobbles beaches, gravel and sandy beaches. The new longshore transport model, joined to an accurate description of local wave conditions, can represent a robust and easy to use instrument to design a coastal structure. The new expression is:

$$
Q_{L T}=\frac{S_{N} D_{n 50}^{3}}{T_{m}},
$$

where $S_{n}$ is a parameter that depends, principally, on the modified stability number (Lamberti and Tomasicchio [31]), $D_{n 50}$ is the $50 \%$ representative grain diameter and $T_{m}$ is the mean wave period.

\subsection{Shoreline evolution behind structures}

Barbaro and Foti [4] carried out some comparisons between the actual profiles of coastline behind a breakwater located in the Natural Ocean Engineering Laboratory (NOEL) of Reggio Calabria, Italy, and the theoretical profiles evaluated through the principal models of static equilibrium available in the literature, which were able to achieve the evolution of the coastline behind a breakwater. More specifically, the static models of Hsu and Silvester [32], McCormick [33], Hsu et al. [34], and Gonzalez and Medina [35] was considered.

The choice of the Reggio Calabria location is due to the characteristics of the sea of Reggio Calabria, where sea states of pure wind-waves with the size of waves achieved in laboratory tanks are frequently realized. The sea waves in Reggio Calabria respect the Froude similarity. The fetch in the NOEL laboratory in the waterfront of Reggio Calabria is limited because of the presence of the Messina coast. This allows for the generation of wind-waves with small amplitudes (about $10 \mathrm{~cm}$ ), which define annual average conditions as very stable over the year so it is possible to assume the coastline facing the laboratory under conditions of static equilibrium.

The coastline profile measured behind the breakwater located at NOEL has been compared with the theoretical profiles achieved through the considered 
models: the significant parameters of the comparison have been the distance between the apex of the salient and the breakwater and the distance between the breakwater and the point of maximum erosion.

Results indicated that the model of Gonzalez and Medina [35] is the most accurate for the location under examination because it renders a good estimate of the distance salient-breakwater, and it provided a small underestimation of the erosion processes in the lateral sides of the breakwater; nevertheless, the effectiveness of the other models in other locations should be considered.

\section{Conclusions}

The prediction and management of shoreline evolution are necessary to protect coasts. Shoreline evolution is caused by many physical factors, such as intensity and duration of sea storm (Arena et al. [5]), design wave (Barbaro [6]), maximum wave forces on structures (Barbaro [7]; Boccotti et al. [8, 9]; Romolo et al. [10]), longshore sediment transport (Tomasicchio et al. [3]), set-up (Barbaro et al. [1]), run-up (Barbaro et al. [2]).

The paper has investigated the main factors involved in the prediction of shoreline change (specifically, the most recent expression for set-up, run-up and longshore transport). The case study of Calabria, by means of the Quantum GIS software, has been discussed. The analysis has focused on the evaluation of the time variation of the shoreline, on the identification of the structures located on the coastline and on their consequences on the shoreline equilibrium.

It has been shown that Calabria is rather complex from an orographic perspective. The anthropogenic effect has been found to be remarkable in the evaluation of the erosion, especially close to the ports.

\section{Acknowledgements}

The authors express their gratitude to the Calabria Basin Authority for providing the data utilized in the present study and for the assistance in the use of the GIS software.

The paper has been partially supported by Regione Calabria, "Dipartimento Istruzione, Alta Formazione, Ricerca", with project "Tutela del Paesaggio e Valorizzazione del Patrimonio Urbanistico nell'area costiera dello Stretto di Messina" TUPA-PUAS.

\section{References}

[1] Barbaro, G., Foti, G. and Malara, G., Set-up due to random waves: influence of the directional spectrum. Proceedings of the $30^{\text {th }}$ International Conference on Ocean, Offshore and Artic Engineering (OMAE), Rotterdam (The Netherlands), 2011. 
[2] Barbaro, G., Foti, G. and Malara, G., A probabilistic approach for the runup estimation. Proceedings of the $5^{\text {th }}$ International Short Conference on Applied Coastal Research (SCACR), Aachen (Germany), 2011.

[3] Tomasicchio, G.R., D’Alessandro, F., Barbaro, G. and Malara, G. A general longshore transport model. Coastal Engineering, 71, pp. 28-36, 2013.

[4] Barbaro, G. and Foti, G., Shoreline behind a breakwater: comparison between theoretical models and field measurements for the Reggio Calabria sea, Journal of Coastal Research, 29(1), pp. 216-224, 2013.

[5] Arena, F., Laface, V., Barbaro, G. and Romolo, A., Effects of sampling between records for intensity and duration of severe sea storms. International Journal of Geosciences, 4(1), 2013.

[6] Barbaro, G., Estimating design wave for offshore structures in Italian waters. International Journal of Maritime Engineering, 164, pp. 115-125, 2011.

[7] Barbaro, G., A new expression for the direct calculation of the maximum wave forces on vertical cylinders. Ocean Engineering, 34, pp. 1706-1710, 2007.

[8] Boccotti, P., Arena, F., Fiamma, V., Romolo, A. and Barbaro, G., Smallscale field experiment on wave forces on upright breakwaters. Journal of Waterway, Port, Coastal and Ocean Engineering, 138, pp. 97-114, 2012.

[9] Boccotti, P., Arena, F., Fiamma, V. and Barbaro, G., Field experiment on random-wave forces on vertical cylinders. Probabilistic engineering mechanics, 28, pp. 39-51, 2012.

[10] Romolo, A., Malara, G., Barbaro, G. and Arena, F., An analytical approach for the calculation of random wave forces on submerged tunnels. Applied Ocean Research, 31, pp. 31-36, 2009.

[11] De Vriend, H.J., Capobianco, M., Chesher, T., de Swart, H.E., Latteux, B. and Stive, M.J.F., Approaches to long-term modelling of coastal morphology: a review. Coastal Engineering, 21(1-3), pp. 225-269, 1993.

[12] De Vriend, H.J., On the predictability of coastal morphology. Proceedings of the $3^{\text {rd }}$ European Marine Science and Technology Conference, Lisbon, Portugal, pp. 289-300, 1998.

[13] Hanson, H. and Larson, M., Comparison of analytic and numerical solutions of the one-line model of shoreline change. Proceedings of the $4^{\text {th }}$ International Conference on Coastal Engineering and Coastal Sediment Processes, New Orleans, Louisiana, USA, pp. 500-514, 1987.

[14] Kamphuis, J.W., Effective modelling of coastal morphology. Proceedings of the $11^{\text {th }}$ Australasian Conference on Coastal and Ocean Engineering, Townsville, Australia, pp. 173-179, 1993.

[15] Hanson, H., Aarninkhof, S., Capobianco, M., Jimenez, J.A., Larson, M., Nicholls, R.J., Plant, N.G., Southgate, H.N., Steetzel, H.J., Stive, M.J.F. and de Vriend, H.J., Modelling of coastal evolution on yearly to decadal time scales. Journal of Coastal Research, 19(4), pp. 790-811, 2003.

[16] Hunt, I.A., Desing of seawalls and breakwaters. Journal of Waterways and Harbours Division, ASCE 85 (WW3), pp. 123-152, 1959. 
[17] Ruggiero, P., Komar, P.D., McDougal, W.G., Marra, J.J. and Beach, R.A., Wave runup, extreme water levels and the erosion of properties backing beaches. Journal of Coastal Research, 17(2), pp. 407-419, 2001.

[18] Sallenger, A.H., Storm impact scale for barrier islands. Journal of Coastal Research, 16(3), pp. 890-895, 2000.

[19] Longuet-Higgins, M.S., The effects of non linearities on statistical distributions in the theory of sea waves. Journal of Fluid Mechanics, 17(3), pp. 459-480, 1963.

[20] Barbaro, G. and Martino, M.C., A new expression of the set-up for random wind generated waves. Proceedings of the $5^{\text {th }}$ International Conference of Coastal Structures. Venice, Italy, pp. 1794-1805, 2007.

[21] Boccotti, P., Arena, F., Fiamma, V., Romolo, A. and Barbaro, G., Estimation of mean spectral directions in random seas. Coastal Engineering, 38, pp. 509-518, 2011.

[22] Pierson, W.J. Jr., and Moskowitz, L., A proposed spectral form for fully developed wind seas based on the similarity theory of S.A. Kitaigorodskii. Journal of Geophysical Research, 69(24), pp. 5181-5190, 1964.

[23] Hasselmann, D.E., Kruseman, P., Meerburg, A., Muller, P., Olbers, D.J., Richter, K., Sell, W. and Walden, H., Measurements of wind wave growth and swell decay during the Joint North Sea Wave Project (JONSWAP). Deutches Hydrographisches Institut, Hamburg, Germany, 1973.

[24] Ochi, M.K. and Hubble, E.N., Six-parameter wave spectra. Proceedings of the $15^{\text {th }}$ International Conference on Coastal Engineering. Honolulu, Hawaii, USA, pp. 301-328, 1976.

[25] Mitsuyasu, H., Tasai, F., Suhara, T., Mizuno, S., Ohkuso, M., Honda, T. and Rikiishi, K., Observations of the directional spectrum of ocean waves using a cloverleaf buoy. Journal of Physical Oceanography, 5(4), pp. 750760, 1975.

[26] Donelan, M.A., Hamilton, J. and Hui, W.H., Directional spectra of windgenerated waves. Philosophical Transactions of the Royal Society of London A, 315(1534), pp. 509-562, 1985.

[27] Boccotti, P., Wave Mechanics for Ocean Engineering. Elsevier Science, Oxford. ISBN 0-444-50380-3, 2000.

[28] Stockdon, H.F., Holman, R.A., Howd, P.A. and Sallenger, A.H. Jr., Empirical parameterization of setup, swash, and runup. Coastal Engineering, 53(7), pp. 573-588, 2006.

[29] Arena, F., Malara, G., Barbaro, G., Romolo, A. and Ghiretti, S., Long-term modelling of wave run-up and overtopping during sea storms. Journal of Coastal Research, 29(2), doi: 10.2112/JCOASTRES-D-12-00050, 2013.

[30] Van der Meer, J.W., Rock slopes and gravel beaches under wave attack. Delft Hydraulics Laboratory, Netherlands. Publication no 396, 1988.

[31] Lamberti, A. and Tomasicchio, G.R., Stone mobility and longshore transport at reshaping breakwaters. Coastal Engineering, 29(3), pp. 263289, 1997. 
[32] Hsu, J.R.C., and Silvester, R., Accretion behind single offshore breakwater. Journal of Waterway, Port, Coastal and Ocean Engineering, 116(3), pp. 367-380, 1990.

[33] McCormick, M.E., Equilibrium shoreline response to breakwaters. Journal of Waterway, Port, Coastal and Ocean Engineering, 119(6), pp. 657-670, 1993.

[34] Hsu, T.W., Jan, C.D. and Wen, C.C., Modified McCormick's model for equilibrium shorelines behind a detached breakwater. Ocean Engineering, 30, pp. 1887-1897, 2003.

[35] Gonzalez, M. and Medina, R., Equilibrium shoreline response behind a single offshore breakwater. Proceedings of the $4^{\text {th }}$ International Conference on Coastal Engineering and Coastal Sediment Processes, Long Island, New York, USA, pp. 844-859, 1999. 